\title{
PEMBUATAN JAKET DENGAN FABRIKASI ARSITEKTURAL UNTUK INDUSTRI KECIL DI JALAN DAMAI
}

\author{
Fermanto Lianto ${ }^{1}$, Denny Husin ${ }^{1}$ dan Yuanda Saputra ${ }^{1}$ \\ ${ }^{1}$ Jurusan Arsitektur Universitas Tarumanagara \\ Email: fermantol@ft.untar.ac.id \\ Email: dennyh@ft.untar.ac.id \\ Email: yuandas@ft.untar.ac.id
}

\begin{abstract}
ABSTRAK
Fenomena tersingkirnya industri kecil dibidang fashion terjadi karena kompetisi global dari busana yang kian kompleks, menempatkan mereka yang berdaya ekonomi lemah dan kemampuan intelektual rendah menghadapi isu tidak bergeraknya sebuah usaha kecil akibat terhimpit oleh keadaan. Masalahnya kemampuan penjahit terbatas pada menghasilkan produk dengan kualitas rendah dan minim kreativitas sangat sulit berkompetisi dengan pemain besar busana. Metode kualitatif digunakan untuk menganalisis keadaan mitra dengan mengangkat kemampuan sederhana yang mereka miliki, untuk diinterpretasikan dan dikembangkan kompleksitasnya. Melalui alat percobaan arsitektural, kemampuan bidang pakaian dikombinasikan secara manual dan digital dengan teknik adjusting pattern dan folding architecture. Minat dan bakat mitra dalam membuat seragam wanita berupa lipit dinilai berpotensi meskipun sesungguhnya merupakan kemampuan dasar teknik pleated. Dengan bantuan peranti lunak, mitra diperkenalkan dengan mesin (lasercutting) dan pengembangan digital (photoshop dan autodesk) sehingga dapat mengelaborasi hasil lipitan menjadi fabrikasi arsitektural berupa jaket. Sebagai temuan, adjusting pattern dan folding architecture dapat dikembangkan melalui kemampuan mitra melipit, baik sebagai tekstur dan detail jaket arsitektural dan menghasilkan kebaruan pola karena memungkinkan modifikasi dengan peranti lunak komputer. Melalui pengetahuan arsitektural efisiensi, presisi dan kreativitas mengisi celah kebutuhan industri yakni; 1) Kebutuhan mitra untuk menambah wawasan mengembangkan teknik lipit dan penyesuaian pola pada pakaian seragam sehingga melihat peluang usaha baru; 2) Industri tekstil untuk menghasilkan variasi pola arsitektural yang lebih kompleks tanpa harus membuat eksperimentasi sendiri; 3) Arsitek dan dosen untuk menggunakan keilmuan pada disiplin ilmu dan industri lain.
\end{abstract}

Kata kunci: Arsitektural, Fabrikasi, Folding, Jaket, Lipit.

\section{PENDAHULUAN}

Jalan Damai, Cipete, Jakarta selatan merupakan salah satu lokasi strategis di Jakarta Selatan. Kedekatan dengan sekolah-sekolah mode terkemuka, konveksi-konveksi dan butik-butik menengah atas, tidak membuat daerah ini menjadi cukup sejahtera. Kenyataannya, jalan Damai merupakan daerah perumahan sangat sederhana, merupakan kombinasi lahan-lahan pribadi semi kumuh yang banyak menyediakan rumah kontrakan, kos-an, usaha informal atau industri kecil. Tempat ini dikenal dengan fenomena tenaga kerja terjangkau bagi mereka yang bekerja atau memiliki usaha kecil sekitar dengan menerima limpahan dari tawaran dari kawasan komersial sekitar.

Dengan bergantung dari limpahan pekerjaan sekitar atau sekedar menerima pekerjaan dari tetangga dan teman, kelompok penjahit industri kecil di jalan Damai menghadapi isu untuk terus melanjutkan usahanya, berganti arah atau sekedar mengulang pekerjaan membuat seragam, emblem atau baju harian sedapatnya. Terdiri dari kumpulan tukang jahit lepasan, ibu rumah tangga dan remaja putri, kumpulan usaha kecil ini sebenarnya cukup fleksibel dalam membagi pekerjaan dengan mengandalkan semangat kekeluargaan. Namun demikian, ketatnya keadaan pasar, kemampuan penjahit di industri kecil jalan Damai kian dipertanyakan. Masalahnya, tawaran semakin langka karena mereka tidak dapat beradaptasi dengan tanggap dengan keadaan pasar sementara kemampuan mereka juga tidak bertambah. 
Pada kenyataannya kumpulan industri kecil ini terdiri dari potensi sumber daya manusia yang besar. Sementara lokasi strategis sudah menjadi keunggulan mereka, kemampuan tektonik lokal dalam membuat pakaian harian sebenarnya dapat diandalkan, namun apa daya dengan keterbatasan ekonomi mereka kesulitan mengembangkan diri menjadi masalah utama mereka (Hadiyatun et al, 2014). Keberadaan kelompok penjahit industri kecil jalan Damai dapat dilestarikan jika pengetahuan tambahan dapat diserap oleh mereka sehingga dapat meningkatkan kemampuan dan daya saing sehingga terus memberikan penghasilan di masa depan (Hamy \& Suryawan, 2009).

Melalui sebuah analisis sosial, kemampuan industri kecil di jalan Damai perlu ditambah apabila mereka berharap untuk dapat beradaptasi dengan kebutuhan pasar yang cepat berubah (Ranelis, 2014). Pakaian sebagai produk kebudayaan adalah identitas yang perlu dijaga, sebuah kegiatan intelektual dengan mengedepankan keterampilan tingkat lanjut dapat membuka mata mereka sehingga bersemangat untuk terus menimba ilmu dan berani mengambil kesempatan (Lyndon et al, 2015) mengembangkan dirinya. Sebuah kegiatan kemasyarakatan dengan memberikan wawasan baru berupa ilmu campuran antara arsitektur dan busana (Koch, 2009). Selain pengetahuan baru ini dapat membuka cakrawala baru mereka, jalinan kerjasama dan perkenalan dengan alumni yang memiliki usaha pakaian dan aksesoris akan memberi kesempatan mereka untuk ujuk kemampuan. Melalui purnarupa dengan kualitas dan kompleksitas tinggi, sebuah kegiatan mengangkat keterampilan sederhana penjahit untuk dielaborasi dengan keilmuan arsitektur. Usaha ini berupaya membuktikan kemampuan penjahit industri kecil jalan Damai agar dapat menaikkan standar produk dengan nilai jual yang lebih tinggi (Townsend, 2005).

Dalam rangka mengkontras ritme yang sama untuk membuat seragam dan pakaian harian, diskusi bersama tentang sebuah alternatif produk kontras yang masih familiar untuk mereka kerjakan adalah membuat jaket dengan fabrikasi arsitektural. Jaket dengan fabrikasi arsitektural merupakan purnarupa keluaran dengan konsep kontradiktif, jaket dengan fabrikasi arsitektural memiliki dua gaya yakni klasik untuk kesan formal dan sport (baca: olahraga) untuk gaya kasual, yang dalam penelitian ini dikembangkan sebagai sebuah kombinasi dari keduanya. Jaket dengan fabrikasi arsitektural mengandalkan struktur pakaian yang dikombinasikan dengan detail hasil aplikasi teknologi sederhana berupa tekstur dan detail dengan tujuan mengkontras aspek skala pada rancangan (Chinwendu, 2014). Kelompok penjahit industri kecil jalan Damai diarahkan untuk merangkai purnarupa dengan struktur dan aksesoris pakaian yang telah dirancang dengan mengandalkan uji coba detail dan tekstur fabrikasi arsitektural. Tujuannya tidak saja memberikan kemampuan baru, namun secara alami melibatkan alumni yang memiliki usaha sejenis untuk mengenal potensi baru dari industri kecil di jalan Damai.

\section{KAJIAN PUSTAKA DAN METODE}

Fabrikasi Jaket merupakan pengembangan creative fabric dengan metode eksperimentasi material pada tekstil menggunakan kombinasi bahan dan teknik arsitektural. Fabrikasi ditekankan pada tekstur dan detail tekstil untuk mengembangkan jaket arsitektural. patterning, pressing, colouring, folding adalah beberapa contoh teknik yang diaplikasi secara arsitektural yang dapat dikombinasikan dengan tekstil untuk kebutuhan proteksi jaket terhadap cuaca. Wool, insulasi yang kerap menjadi bahan pengisi dinding interior juga kerap digunakan pada busana untuk kebutuhan proteksi tubuh meski memiliki spesifikasi yang khusus digunakan dibidang pakaian. 
Dengan metode adjusting pattern, sebuah konsep rancangan jaket dua gaya direalisasikan agar gaya klasik dapat berpadu dengan gaya sport yang memiliki arahan jahit berbeda. Untuk menghasilkan kebaharuan yakni mengembangkan fabrikasi teksur dan detail untuk menyatukan dua gaya yang kontradiktif, sketsa manual digambar ulang dengan menggunakan autodesk cad dan dikembangkan dengan photoshop sebagai bahan presentasi. Kedua pola yakni manual dan digital dapat dicocokkan melalui teknik superimpose sehingga dapat diprediksikan dan dicocokkan perbedaannya sehingga dapat disatukan pada akhirnya. Fabrikasi material menggunakan arahan pola dengan merencanakan perubahan arah, lipatan bahan dan torehan maupun jahitan untuk membuat creative fabric pada kedua sisi yakni luar dan dalam jaket. Dengan teknik serupa, akrilik dan logam sebagai bahan aksesoris pakaian direncanakan potongan dan goresannya (grafir) dengan mesin lasercut dan jahitan tangan.

Kegiatan Penelitian kepada Masyarakat (PKM) ini memperhatikan aspek-aspek fundamental seperti:

\section{a) Bahan}

Pemanfaatan bahan-bahan dasar tetap diperlukan untuk percobaan misalnya kain belacu, kalkir, kertas roti, karton dan hvs selain bahan-bahan ini memang digunakan sebagai alat kerja. Teknik penggambaran manual dikerjakan sebagai proses sketsa, gambar pada kertas roti atau kalkir dicocokkan agar dapat mempertemukan struktur yang berbeda dari dua gaya. Setelah menyatu, proses penggambaran digital dimulai dengan penggambaran ulang pada autodesk $c a d$, sehingga dapat mempertemukan pola dan struktur pakaian secara presisi. Setelah pola dan struktur disesuaikan dengan adobe illustrator cs (lihat gambar 1). Sementara proses menggambar dipresentasikan kepada kelompok penjahit sehingga dapat diserap secara kronologis; penggambaran sketsa manual dipindahkan ke photoshop untuk digrafiskan.

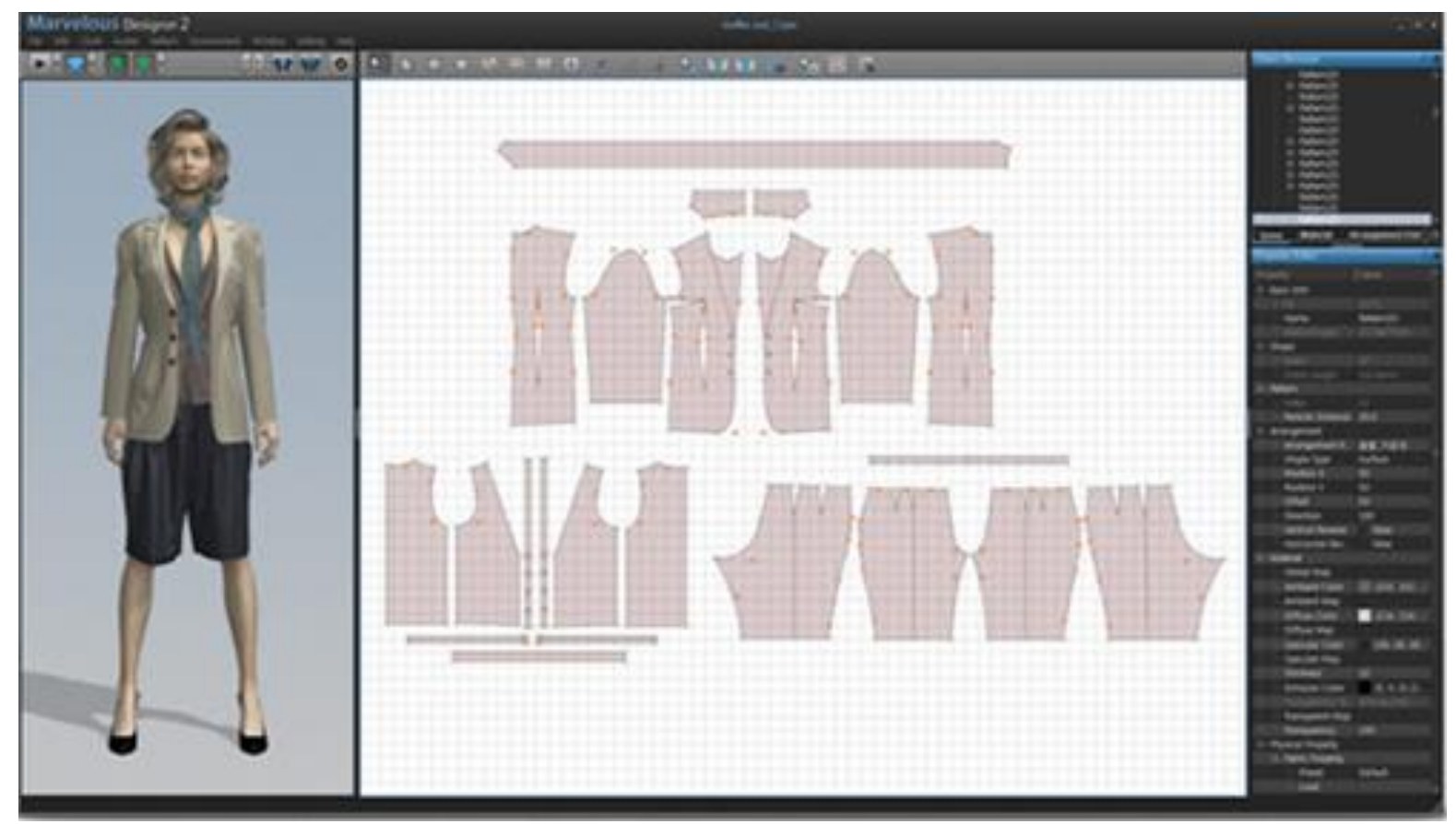

Gambar 1: Contoh Pembuatan Pola dengan Autodesk

Sumber: http://images.connect2communities.com/articles/40753/pic0_40753.jpg diunduh 12 Januari 2019

\section{b) Teknik Adjusting Pattern}

Teknik adjusting pattern digunakan untuk menyesuaikan ukuran atau bentuk pakaian dengan cara membongkar pola, dan menyesuaikan ukurannya sesuai keperluan. Pada kegiatan PKM ini, teknik adjusting pattern digunakan untuk menyatukan struktur pakaian dua gaya dan 
membuat fabrikasi dua sisi pada jaket sehingga dapat menyatu (lihat gambar 2). Sementara struktur pakaian diterjemahkan melalui pola, creative fabric adalah manipulasi kreatif pada permukaan pakaian dengan mengkreasikan tekstil, dekorasi, aksesoris dan lain-lain. Manipulasi tekstil pada hal ini akan disesuaikan dua arah pola sehingga sinkron dan menyatu antara gaya klasik dan sportif yang sebenarnya kontradiktif (lihat gambar 3). Fabrikasi creative fabric dapat menggunakan pola untuk menghasilkan tekstur tiga dimensional dan mengubah keseluruhan tampilan dan siluet pakaian. Untuk memudahkan proses kerja, maka potongan pakaian dan aksesoris pada purnarupa dikerjakan dengan lasercuting melalui proses yang didokumentasikan dan disaksikan oleh kelompok penjahit. Selain proses pengerjaan ini dapat menghemat waktu dan bahan, penjahit diterjunkan langsung ke studio dan workshop untuk mengalami langsung untuk melihat contoh dan simulasi proses pekerjaan dengan teknologi. Namun demikian demi mengangkat kemampuan menjahit mereka, perjahitan akhir dikerjakan oleh kelompok penjahit industri kecil jalan Damai.

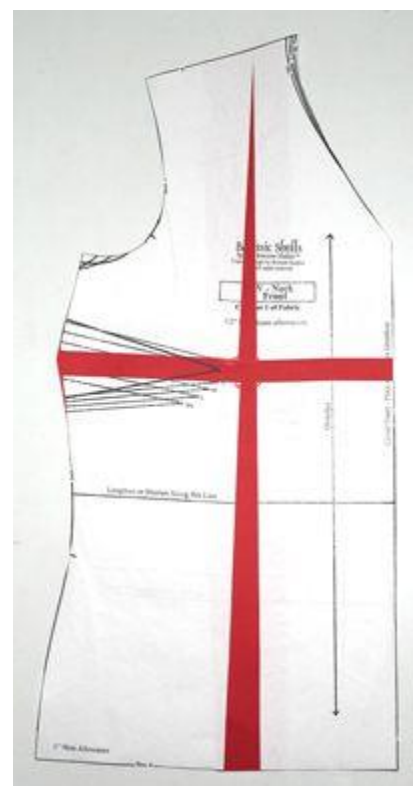

Gambar 2. Contoh Teknik Adjusting Pattern Model Cubitan pada Pola Pakaian Sumber: https://i.pinimg.com/236x/e0/84/d4/e084d4ef9b48926c05eb4f5d01deca9d--sewing-tutorialssewing-tips.jpg diunduh 12 Januari 2019

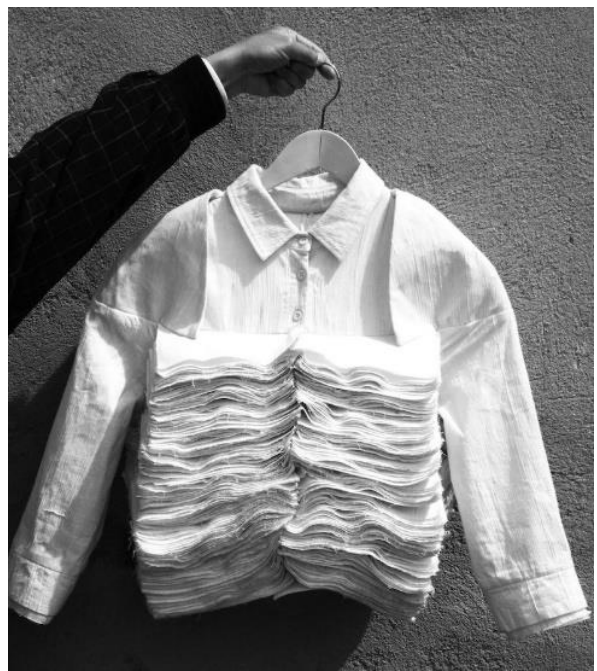

Gambar 3. Contoh Pola dan Manipulasi Tekstil

Sumber: http://madamebarry.tumblr.com/post/23610014535 diunduh tanggal 12 Januari 2019 


\section{c) Purnarupa}

Purnarupa akhir merujuk pada ukuran pragawati, yakni model size. Proporsi jaket ditargetkan untuk presentasi ketinggian wanita $172 \mathrm{~cm}-180 \mathrm{~cm}$ (European general size) sebagai patokan. Purnarupa dibentuk menggunakan sketsa awal dengan material belacu, difinalkan dengan kombinasi katun stretch dan pita olah raga. Fitting dilakukan sesuai standar perancang, menggunakan model standar ESMOD. Purnarupa yang telah dikerjakan dijadikan sample untuk ditiru penjahit. Penjahit akan memulai fabrikasi dari pola dasar, perencanaan lapisan struktural, pembuatan creative fabric, pola final, penyusunan, penjahitan jaket. Hasil akhir yang dikerjakan oleh penjahit akan melalui quality control dari pihak perancang sehingga mendapatkan review dan masukan. Alternatif dan pengembangan lain dapat dijabarkan sebagai masukan sehingga memberikan celah kreasi baru sebagai strategi keberlanjutan (Joy et al, 2012).

\section{HASIL DAN ANALISIS}

Analisa usaha dan kemampuan mitra dalam memproduksi pakaian merujuk pada infomasi mengenai: 1) Industri kecil Jalan Damai didominasi pekerja lepasan yang merupakan ibu rumah tangga dan remaja putri yang bekerja tambahan untuk mendapatkan uang jajan atau uang tambahan harian; 2) Kegiatan industri kecil ini didominasi dengan pekerjaan membuat seragam, emblem atau baju harian. Pola dasar dimainkan dengan mengubah arah dan orientasi, baik untuk merubah ukuran maupun bentuk secara sederhana; 3) Permainan pola ini merupakan teknik penyesuaian pola (adjusting pattern) yang diterapkan secara sederhana, namun mendominasi teknik yang digunakan mitra dalam membuat pakaian seragam. Temuan lain yang dominan adalah ketertarikan mitra membuat lipit khususnya pada rok dan kemeja untuk membentuk tekstur dan cubitan pada pakaian (lihat gambar 4). Temuan ini serupa dengan teknik folding yang kerap digunakan pada teknik arsitektur karena terinspirasi oleh origami.
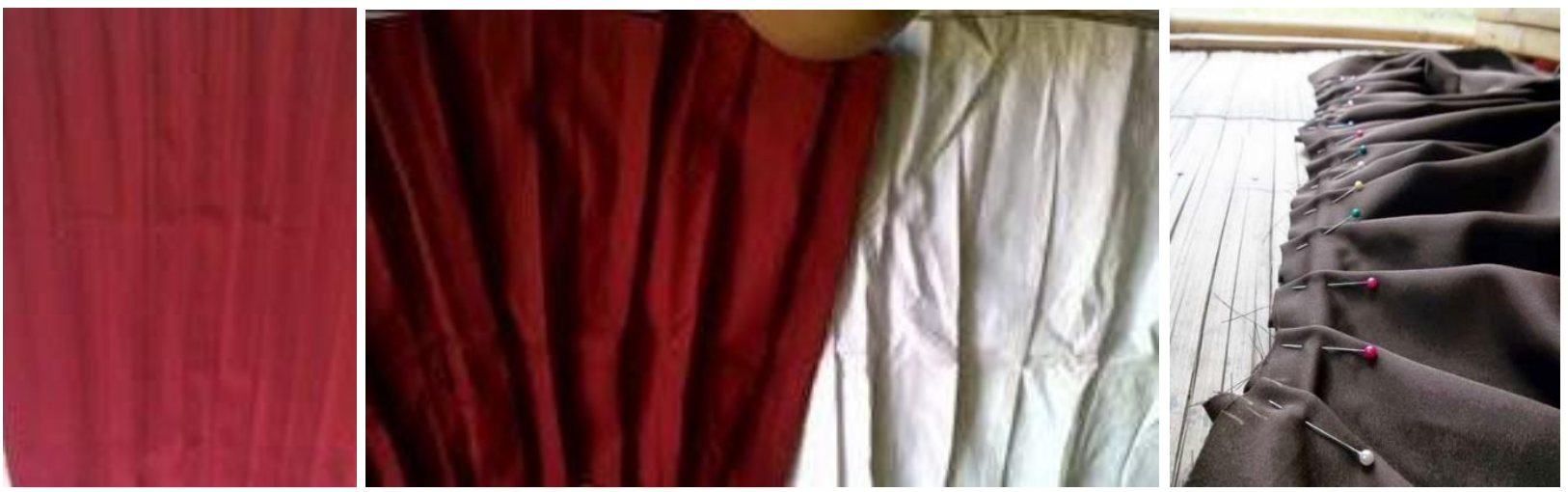

Gambar 4. Contoh Metode Manual Membuat Rok Lipit.

Sumber: Tim PKM, 2019

Dengan menganalisa kekuatan dan potensi mitra dalam mengerjakan kegiatan harian. Solusi permasalahan ditanggapi dengan mengkombinasi disiplin ilmu arsitektur dan busana dengan perancang yang kerap bekerjasama dengan mitra. Perancang busana membantu membuat sketsa agar dapat memberikan gambaran umum terhadap target fabrikasi yakni tekstur dan detail jaket. Hal ini ditujukan untuk memudahkan pembacaan mitra terhadap sketsa pola fabrikasi dan detail yang diinginkan. Melalui perembukan, sebuah jaket arsitektural ditargetkan sebagai hasil akhir eksperimentasi, produk asing bagi mitra, namun mengembangkan keterampilan yang sudah ada karena kerap membuat seragam baik yang klasik maupun olahraga. Kemampuan adjusting pattern dan folding yang kerap dilakukan mitra, dielaborasi untuk menghasilkan sebuah 
eksperimentasi fabrikasi pada tekstil yang nantinya dapat dipilih atau dikembangkan dalam membuat jaket sebagai hasil akhir (lihat gambar 5). Bukan tidak mungkin metode ini diperkuat dengan jenis detail dan metode yang lebih arsitektural.

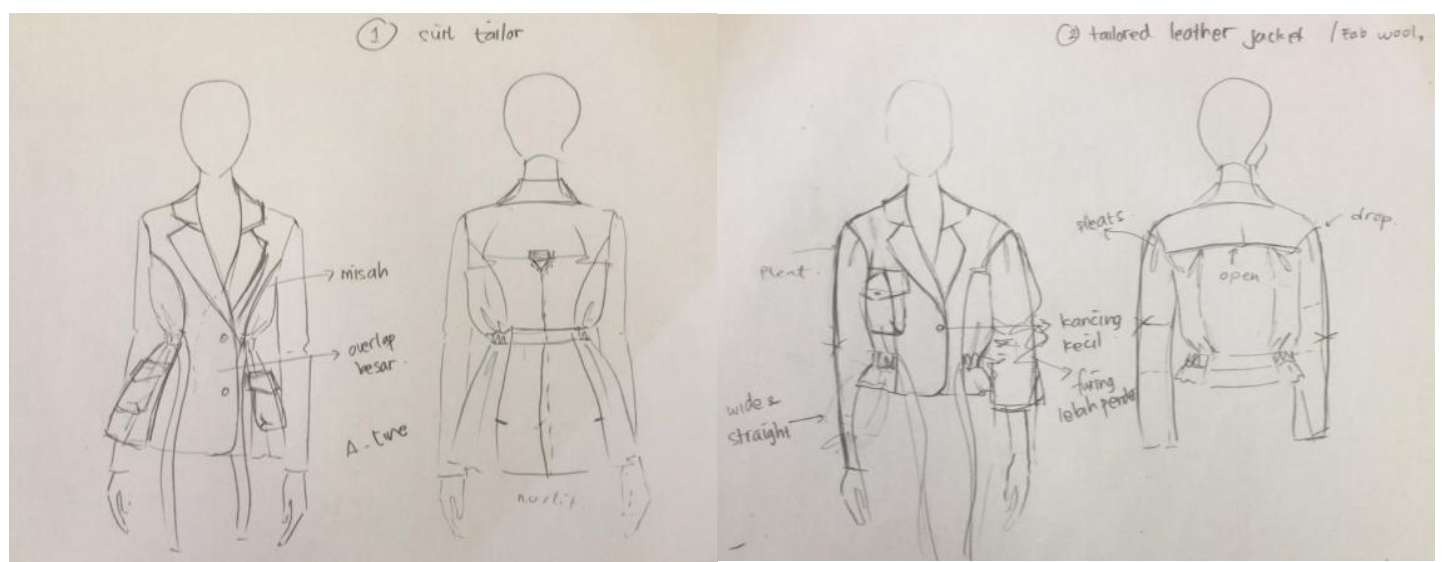

Gambar 5. Sketsa Jaket dengan Fabrikasi Arsitektural Pengembangan Penyesuaian Pola \& Lipit

Sumber: Tim PKM, 2019

Teknik adjusting pattern dan folding dimulai dengan membuat sketsa cad. Autodesk cad membantu menggambarkan pola, dimulai dengan geometris sederhana dengan mengambil contoh-contoh dari pola sederhana seperti garis maupun permainan kompleks berbasis parametrik sederhana. Dengan melakukan scan terhadap pola-pola yang sederhana yang pernah dibuat sebelumnya, photoshop membantu memperjelas hasil dan transfer gambar. Kelebihan dan kekurangan pola dasar yang pernah dilakukan sebelumnya dapat dijadikan tinjauan dalam melakukan eksperimentasi. Kekuatan dan kekurangan ini dapat menjadi pertimbangan dalam menghantar eksperimentasi agar dapat bergradasi. Pola geometris sederhana direplikasi dengan cad kemudian dimanipulasi dengan adobe illustrator cs. Sebuah rangkaian eksperimentasi mengikuti pola fabrikasi sederhana yang telah dibuat agar mitra dapat membayangkan dengan mudah hasil akhirnya (lihat gambar 6).

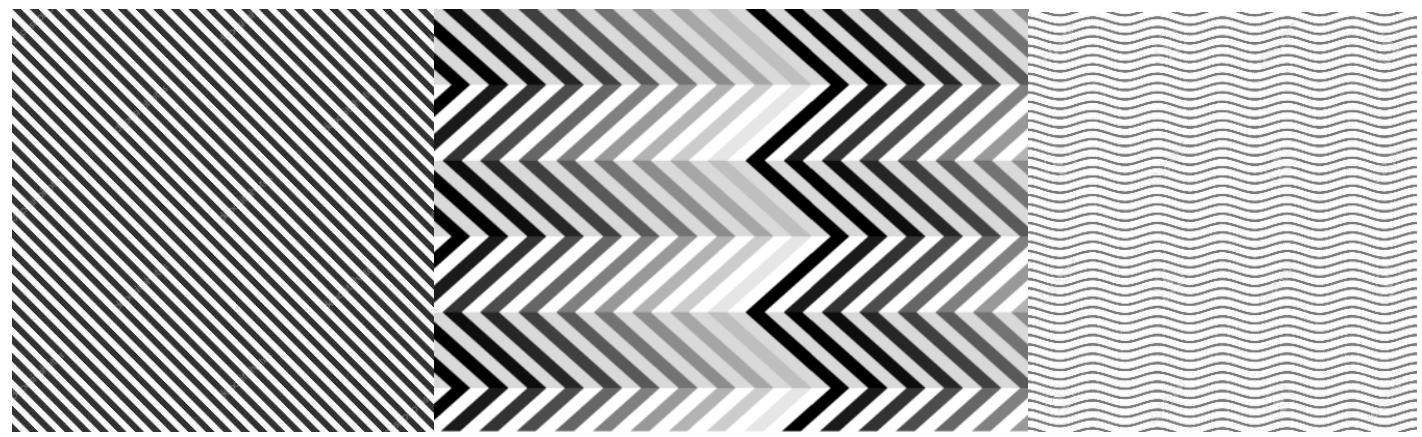

Gambar 6. Contoh Manipulasi sebagai Pengembangan Pola Penyesuaian pada Fabrikasi Arsitektural

Sumber: Tim PKM, 2019

Pola yang telah dihasilkan diujicoba secara manual oleh mitra dengan teknik sederhana, kolaborasi dengan perancang busana membantu memberikan pengetahuan pada variasi teknik manual. Mitra dan perancang busana diajak untuk memodifikasi dan memanipulasi pola digital agar dapat memberi arahan fabrikasi yang dapat diekperimentasikan. Dengan variasi kompleksitas yang beragam, dan tingkat kesulitan yang tinggi dalam membuat fabrikasi. Teknik manual dengan menggunakan setrika panas dan obat plisket merujuk temuan berupa 
ketidakpresisian dan dan ketidakmungkinan membentuk variasi yang rumit. Maka dari itu tim PKM, mitra dan perancang sepakat menggunakan pleated machine untuk menguji coba pola-pola yang telah diuji coba (lihat gambar 7).

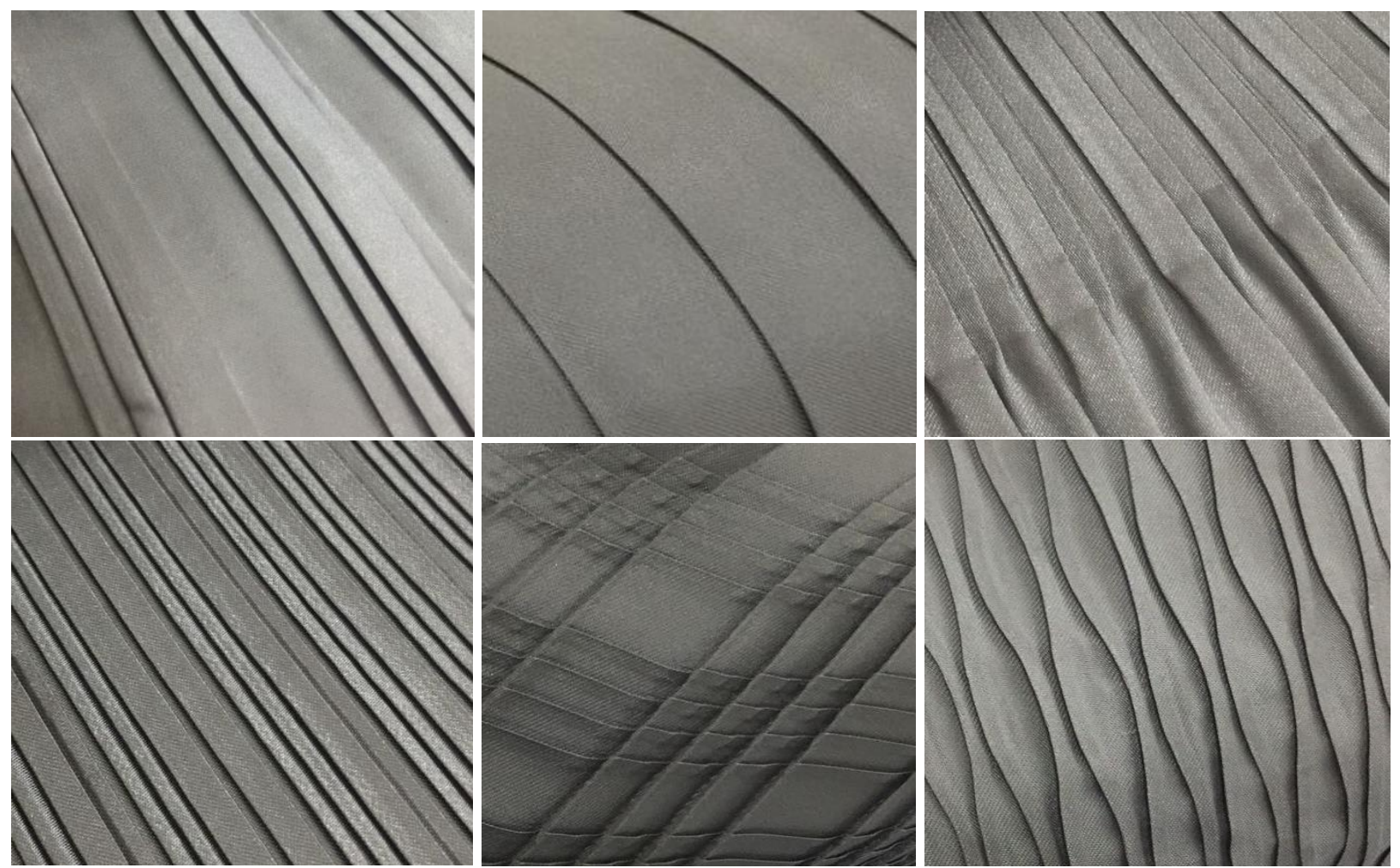

Gambar 7. Contoh Eksperimentasi berupa Fabrikasi Pengembangan Pola Arsitektural dengan

Mesin

Sumber: TimPKM, 2019

Pola dan ekperimentasi lipit manual yang telah diuji coba, dikonsultasikan dengan teknisi pleated machine untuk kemudian disesuaikan dan diperhitungkan parameter lipatan (folding). Melalui beberapa uji coba, beberapa pola mengalami kegagalan minor, kesalahan mayor dan penyesuaian struktural untuk mendapatkan hasil mendekati sketsa. Beberapa variasi dikembangkan teknisi untuk memberikan gradasi variasi. Hal ini dapat menjadi pembelajaran pengembangan lipit dan penyesuaian pola kepada baik Tim PKM, mitra dan perancang busana. Karena beberapa pola dianggap menarik, hasil uji coba dijadikan sampel bagi workshop untuk ditawarkan oleh pelanggan mereka. Hal ini menjadi sumbangsih lain pada kegiatan PKM ini.

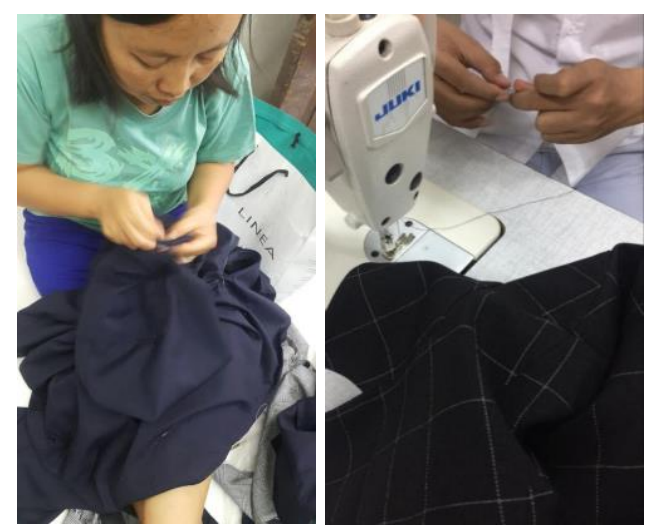

Gambar 8. Proses Pembuatan Prototipe Sumber: TIM PKM, 2019 
Dengan adanya uji coba penyesuaian pola dan lipit, maka dari itu terdapat dua buah kemungkinan yang dapat diimplementasikan pada fabrikasi jaket arsitektural. Yakni;1) Tekstur tiga dimensional tekstil pada jaket arsitektural; 2) Detail lipit bersifat statik dan dinamik pada jaket arsitektural; 3) Kombinasi tekstur dan detail lipit bersifat statik maupun dinamik pada jaket arsitektural.

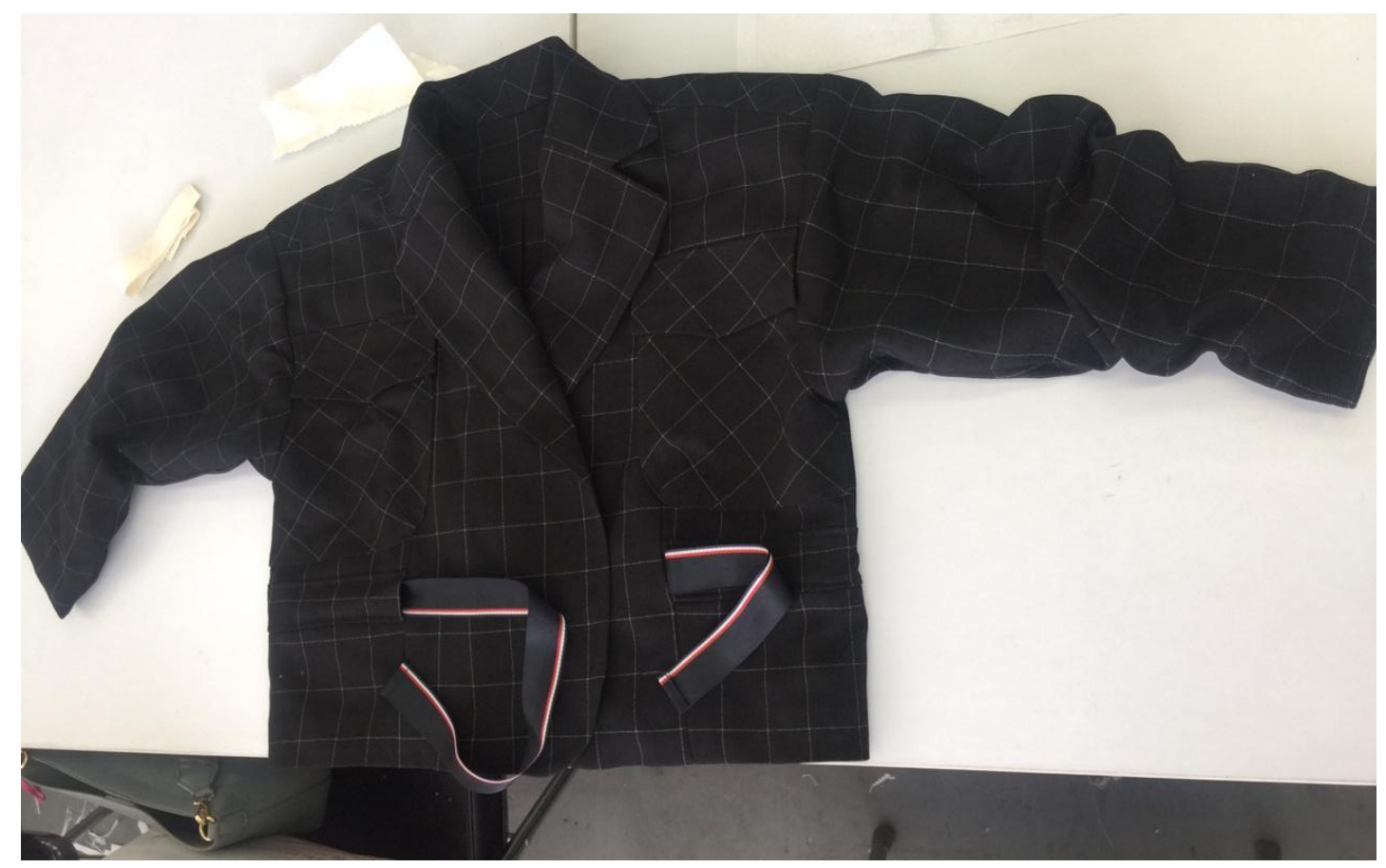

Gambar 9. Finalisasi Prototipe

Sumber: TIM PKM, 2019

\section{KESIMPULAN}

Kegiatan PKM mengembangkan kemampuan mitra dengan mengangkat keterampilan dan minat yang dimiliki mitra dalam membuat seragam dan pakaian harian. Kegiatan ini ditujukan untuk membuat fabrikasi arsitektural untuk membuat creative fabric untuk menghasilkan jaket arsitektural menggunakan teknik manual dan mesin dengan bantuan software dan teori arsitektural yang mengetengahkan pattern structure dan folding architecture. Melalui pengetahuan arsitektural efisiensi, presisi dan kreativitas mengisi celah kebutuhan industri yakni; 1) Kebutuhan mitra untuk menambah wawasan mengembangkan teknik lipit dan penyesuaian pola pada pakaian seragam sehingga melihat peluang usaha baru; 2) Industri tekstil untuk menghasilkan variasi pola arsitektural yang lebih kompleks tanpa harus membuat eksperimentasi sendiri; 3) Arsitek dan dosen untuk menggunakan keilmuan pada disiplin ilmu dan industri lain.

\section{Ucapan Terima Kasih}

Terima kasih kepada pihak Kelompok penjahit industri kecil jalan Damai, Bareskin dan Direktorat Penelitian dan Pengabdian Kepada Masyarakat Universitas Tarumagara yang telah memfasilitasi hingga terlaksananya kegiatan PKM ini. 


\section{REFERENSI}

Chinwendu, A. U. (2014). Architecture + Fashion: A Study of the Connection between Both Worlds. Dissertation for Master of Architecture. Notthingham Trent University.

Hadiyatun, M. I. et al. (2014). Arsitektur di Indonesia dalam Perkembangan Jaman, Sebuah Gagasan untuk Jati diri Arsitektur di Indonesia. Universitas Kristen Petre \& Institut Teknologi Sepuluh Nopember.

Hamy, S. \& Suryawan, D. S. (2009). Chic Mengolah Wastra Indonesia: Batik Jawa Barat. Jakarta: PT. Gramedia Pustaka Utama.

Joy, A. et al. (2012). Fast Fashion, Sustainanility, and the Ethical Appeal of Luxury Brands. Fashion Theory, Volume 16, Issue 3, pp. 273-296 DOI: 10.2752/175174112X13340749707123. Berg.

Koch, D. (2009). Architectural Fashion Magazines Ref 057. Proceedings of the 7th Internasional Space Syntax Symposium. Stockholm: KTH.

Lyndon, N. et al. (2015). Cultural and Language Identity of the Thesaban Takbai Malay Ethnic, Southern Thailand: A Phenomenological Analysis. Mediterranean Journal of Social Sciences, Vol 6 No 4 S3. Rome: MCSER Publishing.

Ranelis. (2014). Seni Kerajinan Bordir Hj. Rosma: Fungsi Personal dan Fisik. Jurnal Ekspresi Seni: Jurnal Ilmu Pengetahuan dan Karya Seni, ISSN: 1412-1662, Volume 16, Nomer 1. Padang Panjang.

Townsend, Orta, L. (2005). Art, Fashion and Mobility. Temporary interventions in Space. Art \& architecture Journal, No 62, Summer, London, 0037-39. UK. 